\title{
The Role of the Institutional Websites on Students' School Choice: A Comparison for the Higher Education Levels in Tourism
}

\author{
Şirvan Şen DEMIR*
}

Received: 10 June 2013

\author{
Mahmut DEMIR ${ }^{* *}$
}

Accepted: 26 June 2014

\begin{abstract}
The purpose of present research is to investigate the effects of the information on tourism higher education institutions' websites on students' school choice. Appropriate to the research model, 5-point Likert type survey has been prepared. The data is collected from associate degree, undergraduate and graduate level students at public universities in 6 provinces for the academic years of 2011-2012 and 2012-2013 through face to face to interviews as well as email and social media with structured surveys. Obtained data have been analyzed via PASW 18.0 statistical software. The factor analysis, correlation analysis, ANOVA and regression analysis were used. All variables are found to be positively correlated with each other. The results of regression analysis show that institutional image and access to information are the determining factors of students' school choice at every level higher education. The impact of facilities and academic staff shows variety according to the level higher education.
\end{abstract}

Keywords: tourism education, websites of schools, school choice decision

\section{Extended Abstract}

Purpose and Significance: The purpose of present research is to investigate the effects of the information on tourism institutional websites on students' school choice. At this age, as a result of technological innovation, access to right information facilitates every aspect of human life. Technology, which is used at every level of production and consumption, enables effective interaction between masses and government institutions, and businesses. In this respect, the internet is one of the most important information technologies. The internet as an institutional communication tool provides internal and external interaction to its providers and users. This study is a significant road map not only to help higher education institutions to reach qualified students but also to facilitate students with their school choice.

Methods: The variables in questionnaire have been adapted from the previous researches of literature. This model fits to the goal of this research with its reliability and validity. The model is constructed with 21 "Likert" type questions within four determinants. There are two questions related to the dependent variable. Likert type questions are designed in a 1 to 5 scale (1=completely disagree, 5=completely agree).

\footnotetext{
Corresponding Author: Assoc. Prof. Dr., Suleyman Demirel University, Isparta, Turkey, sirvansendemir@gmail.com

Assoc. Prof. Dr., Suleyman Demirel University, Isparta, Turkey, mdemir1@gmail.com
} 
The data were collected from associate degree, undergraduate and graduate level students at public universities in Konya, İzmir, Mugla, Isparta, Antalya and Mersin provinces for the academic years of 2011-2012 and 2012-2013 through face to face to interviews as well as email and social media with structured surveys. The survey did not include demographics of the respondents. Out of 600 surveys distributed, 396 of them were included in the sample.

The data are analyzed with PASW 18.0 statistical software and the statistical results are reported by tables. Although the reliability and validity of the model have been confirmed, the results are replicated with a larger sample of respondents. The sample reliability is also tested with the same analysis. At the second stage, respectively, factor analysis, correlation analysis, ANOVA and regression analysis are conducted.

Results: The findings of the study are reported through tables. The findings are at generally accepted confidence level in social sciences $(\alpha=.89)$. At the factorial analysis 5 groups of determinants, which are institutional image, facilities, academic staff, access to information and choice decision, are statistically significant. At the correlation analysis, these determinants are found to be positively correlated with one another at a statistically significant level. At the third stage, ANOVA tests are conducted to determine whether or not level of education of the respondents makes a significant impact. A Scheffe test is executed in order to determine the significance of these differences. And the result of the test shows that level of higher education has an impact on all determinants expect for facilities. At the final stage, results of regression analysis shows that institutional image and access to information are the determining factors of students' school choice at every level higher education. The impact of facilities and academic staff shows variety according to the level higher education.

Discussion and Conclusions: The impact of institutional image on students' choice of higher education institution can be explained by the psychological satisfaction during their education as well as the potential benefits at the job market. The higher impact of institutional image on graduate level students can be explained by their goal of working in academia and desire to have diploma from a more reputable institution. On the other hand, the impact of facilities being more important for associate degree students than graduate students proposes that the level of education makes a difference in school choice.

As a result, it has been concluded that two dimensions of independent variables in three levels have a completely effect on dependent variable while other two dimensions of independent variables in two levels not. The information about academic staff that is presented at websites of higher education institutions impacts students' choice although there are exceptional cases. While the information on academic staff presented at institutional website impacts students' choice at undergraduate and graduate level, it does not have significant impact on associate degree students. In 
conclusion, it is found that students consider the information on institutional websites while making their school choice but this is contingent upon the education level of the student. The findings of this research is related to the education level of students and limited to higher institutions in tourism field at public universities. Therefore, the findings cannot be generalized to students in other fields and private universities. The next step to this study is to conduct a similar research that includes private universities and other fields of higher education. 


\title{
Öğrencilerin Okul Seçiminde Kurumsal Internet Sitelerinin Rolü: Turizmde Yükseköğrenim Düzeylerine Göre Bir Karşılaştırma
}

\author{
Şirvan Şen DEMIR* $\quad$ Mahmut DEMIR**
}

Makale Gönderme Tarihi: 10 Haziran 2013

Makale Kabul Tarihi: 26 Haziran 2014

ÖZET: Bu çalışmanın amacı turizm yükseköğretim kurumlarının internet sitelerinde yer alan bilgilerin öğrencilerin seçim kararları üzerindeki etkisini belirlemektedir. Araştırmanın modeline uygun 5'li Likert türü bir anket hazırlanmıştır. Veriler 2011-2012 ve 2012-2013 eğitim-öğretim yıllarında 6 farklı şehirde bulunan devlet üniversitelerinin turizm bölümlerinde okuyan Önlisans, Lisans ve Lisansüstü öğrenim düzeylerindeki öğrencilerden yüz yüze, e-posta ve sosyal medya aracılığıyla elde edilmiştir. Elde edilen veriler PASW 18.0 istatistik programı ile analiz edilmiştir. Faktör analizi, korelasyon analizi, ANOVA ve regresyon analizi kullanılmıştır. Çalışmada 5 faktör grubu ve tüm grupların birbiriyle pozitif yönlü ilişkisi olduğu bulunmuştur. Regresyon analizi sonuçları, öğrencilerin okul seçim kararları üzerinde kurumsal imaj ve bilgiye ulaşım faktörlerinin tüm öğrenim düzeylerinde etkili olduğunu, akademik kadro ve fiziki olanaklar faktörlerinin birbirinden farklı sonuçları olduğunu ortaya koymuştur.

Anahtar sözcükler: turizm eğitimi, okulların internet sitesi, okul seçim kararı

\section{Giriş}

Günümüzde, teknolojinin etkin bir şekilde kullanılmasıyla doğru bilgilere ulaşıldığında insan yaşamına çok fazla kolaylıklar sağladığı kabul edilmektedir. Üretim süreçlerinden tüketimin son aşamasına kadar yoğun bir şekilde kullanılan teknolojinin, özellikle kurum ve işletmelerin hedef kitlelere ulaşmada önemli bir araç olarak kullanılması karşılıklı etkileşimin oluşmasına da katkı yaratmaktadır. Bu gelişmelerin belki de en önemlisi, bilgi teknolojileri çerçevesinde internet ve internete bağlı donanım ve kullanımlardır. Kurumsal iletişim aracı olarak kullanılan internet siteleri, hem içsel hem de dışsal etkileşim sağlaması nedeniyle oldukça önemli bir kaynak olarak sunuculara ve kullanıcılara değer katmaktadır.

Bireyin sosyal yaşamı ve kültürü üzerinde birtakım olumlu ya da olumsuz değişimlere yol açtığı bilinen internetin, toplumsal yapı üzerinde etkileri giderek artmakta (Demir ve Demir, 2012), dünya, internetle bilgi ağırlıklı bir iletişim sisteminin içine doğru yol alırken, internetin geniş kitlelere ulaşması nedeniyle bilgi paylaşımı hızla yayılmaktadır (Sarıfakıoğlu, 2013). İş ve sosyal yaşamda iş, oyun, bilgi arama, iletişim, paylaşım vb amaçlarla vazgeçilmez bir unsur olarak kullanılan internet, bireyleri kendine bağlayan, kimine göre monotonluk ve tembelliğe, kimine göre hareketlilik ve özgürlük sağlayan özelliğiyle son derece önemli hale gelmiştir.

İnternetin olumlu etkileri dikkate alındığında, bilgi aramada kullanılan önemli bir araç olarak, doğruluğu kesinleşmemiş dahi olsa, sınırsız kaynak erişimi ve bilgi paylaşımına olanak sağlamada en kolay, hızlı ve pratik yol haline gelmiş olması, bireylerin seçenekler arasındaki tercihlerinde karar verme sürecini de olumlu

\footnotetext{
* Sorumlu Yazar: Doç. Dr., Süleyman Demirel Üniversitesi, Isparta, sirvansendemir@gmail.com

** Doç. Dr., Süleyman Demirel Üniversitesi, Isparta, mdemir1@gmail.com
} 
etkileyebilmektedir. Günümüzde hızlı yaşamın firsatlarını en iyi şekilde değerlendirmek için en önemli araç konumunda olan internetin (Demir ve Demir, 2003) en büyük özelliği, birey ile bilgi arasındaki mesafeyi ortadan kaldırmasıdır (Coşkun, 2004). Bu konudaki en önemli olumsuzluk; internette yer alan tüm bilgilerin güncelliği, doğruluğu ve geçerliliğinin kesin olmaması karar verme sürecinde yanlış tercihlerin yapılmasını ve buna bağlı olarak telafisi güç sonuçların oluşmasına neden olabilmektedir. Özellikle tüketici kararları açısından son derece öneme sahip kurumsal kaynaklı bilgiler, aynı zamanda kurum ve işletmelere de önemli avantajlar yaratmaktadır.

$\mathrm{Bu}$ çalışmada yer alan tüketici kavramı ile ifade edilenler, öğrencilerdir, kurum olarak ifade edilen ise Yükseköğretim Kurumlarıdır. Literatür taraması ve araştırma bölümleri bu bilgiler çerçevesinde ele alınmakta ve değerlendirilmektedir. Bu nedenle, çalışma turizm eğitimi veren Yükseköğretim Kurumlarının internet sitesinde yer alan bilgilerin öğrencilerin okul seçimi kararlarına etkisi üzerine kurgulanmıştır. Öğrencilerin okul tercihinde kurumsal internet sitesindeki bilgilerin seçim kararları üzerindeki etkisinin incelendiği bu çalışma, kavramsal ve araştırma bölümleri olmak üzere iki bölümde açıklanmaktadır. Bu çalışma hem Yükseköğretim Kurumlarının nitelikli öğrencileri bulması, hem de öğrencilerin hedefleri doğrultusunda doğru okulu seçmesi konusunda yapılacak düzenleme ve taraflara yol göstermesi açısından önem taşımaktadır.

\section{Literatür Taraması}

Bireyler gereksinim duyduğu ürün ya da hizmet için öncelikle bilgi aramaya başlar ve bilgiye ulaşmak için çeşitli arama yollarına girer. Elde edilen bilgiler öncelikle doğrulanmak amacıyla zihinde ve çevresel aktörler yardımıyla değerlendirilir. Bilgi arama sürecinde yeterli görülemeyen durumlarda, farklı kaynaklar ve kanallar yardımıyla bu süreç tekrarlanır (Demir ve Demir, 2012). Çünkü bilgi arama aşamasında bireyler daha iyi kararı verebilmek için aktif olarak bilgi toplamaktadır (Hastings ve Weinstein, 2008). Bu nedenle bilgi arama, herhangi bir kararı vermeden önce birçok kaynağa başvurarak verilmesine uygun karar için çevredeki mümkün olabilen bilgileri toplama süreci olarak da açıklanmaktadır (Bussel, 1998; Schneider, Teske ve Marschall, 2002).

Bu kapsamda tüketici konumunda olan öğrencilerin de bilgi arama süreci farklı değildir. En iyi ve doğru tercihi yapabilmek için öğrencilerin öğrenim gördüğü okul ve dershanelerden edindikleri bilgiler dışında, öğrenim görmek istedikleri Yükseköğretim Kurumlarının resmi internet sitelerinde de bilgi aramayı gerçekleştirdikleri bilinmektedir. Diğer yandan, Yükseköğretim Kurumlarının daha nitelikli öğrencileri kendi birimlerine çekebilmek için bir çeşit tanıtım ve pazarlama çalışmaları içinde oldukları da bir gerçektir (Demir ve Demir, 2012). Öğrencilerin eğitim hizmetinden yararlanması için karar verme ve seçim sürecini etkin bir şekilde değerlendirerek bilgiye ulaşması oldukça önemlidir. Çünkü bilgi arama sürecinde elde edilen kurumsal kaynaklı bilgiler öğrencilerin kararlarında etkili olabilmektedir (Weiher ve Tedin, 2006). Bu nedenle onlara doğru bilgiyi, doğru şekilde, doğru zamanda ve doğru yerde sunmak oldukça önemlidir (Bussell, 2000; Hoxby, 2003; Hoxby, 2007; Werthner ve Klein, 
1999). Bilgi arama, aynı zamanda tercihlerde risk ve zihinde oluşan kuşku unsurunu azaltarak doğru seçim ve karar vermeyi kolaylaştırması nedeniyle bireyin karşılaştı̆̆ belirsizlikleri ortadan kaldırmaktadır (Abdulkadiroğlu ve Sönmez, 2003; Chen ve Sönmez, 2006; Demir ve Demir, 2012). Bu da bilgi aramanın karar verme sürecinde nedenli önemli olduğunu ortaya koymaktadır.

Öğrencilerin internet üzerinden kurumsal kaynaklı bilgiye kolaylıkla ulaşmaları, Yükseköğretim Kurumlarını karşılaştırarak karar vermelerine de katkı sağlamaktadır. Son yıllarda Yükseköğretim Kurumlarının liseler, dershaneler gibi potansiyel pazarlara yönelik yapmış oldukları tanıtım çalışmalarına karşılık, öğrencilerin de bilinçli bir şekilde kurum hakkında daha fazla bilgiye ulaşma isteği, kurumsal internet sitelerinin kullanımını arttırmaktadır (Demir ve Demir, 2012). Çünkü kurumların eğitim-öğretim faaliyetlerinin yanında, burs, barınma, spor, yeme-içme ile ilgili fiziki yapı, sosyal alan olanakları ve koşulları gibi kurumsal bilgilerin de yer aldığ internet siteleri, öğrencilerin tercih aşamasında verecekleri kararları etkileyebilmektedir. İnternetin gerek bireyler ve kurumların kendi aralarında gerekse bireyler ile kurumlar arasında bilgi aktarımını farklı şekillerde sağlaması (Bonn, Furr ve Susskind, 1998) harcanan çaba sonucunda çıktılara etki ettiğini göstermektedir.

Bilgi arama sürecinde bireyleri etkileyen pek çok farklı unsurun olması sürecin basit olmadığını göstermektedir. Hedeflenen bilgiye ulaşma sırasında karşılaşılacak ilgi ve dikkat çekebilecek başka bilgiler, bireylerin karar vermesinde birtakım kargaşa yaşanmasına da neden olabilmektedir. Bir kısmı görsel, bir kısmı içerik açısından bireyleri etkilemesi nedeniyle kurumsal yapıdaki internet sitelerinde bilginin düzenlenişi, sunumu, kişinin bilişsel yapısı ve bilgi arama davranışı gibi unsurlar tercihlerde etkin olabilmektedir (Demir ve Demir, 2012; Uçak ve Güzeldere, 2006).Bu konuda yapılan çalışmalar (Yolal ve Kozak, 2008; Whitmore, 2002), öğrencilerin bilgi gereksinimlerinin ve bilgi arama davranışlarının, içinde bulundukları ortam, farklı akademik disiplin ve sahip oldukları olanaklara, amaç ve kullanım alanlarına bağlı olarak değişebileceğini göstermektedir.

Öğrencilerin Yükseköğretim Kurumlarının internet sitesi üzerinden eriştikleri bilgilerin doğru ve güvenilir olduğunu düşünerek yapmış oldukları tercihlerde zaman zaman birtakım olumsuzluklarda yaşanabilmektedir. Bu bilgilerin bir kısmının, örneğin akademik bilgiler, geçerliliğinin deneyimlenmeden belirlenmesi oldukça zor ve bu konuda yapılan değerlendirmeler de özneldir. Buna karşın tercih aşamasında pek çok öğrencinin kurumsal internet sitesi bilgilerine ek olarak özellikle yakın şehirlerdeki okulların fiziki durum ve uygulama alanları ile sosyal tesis olanaklarını görme eğiliminde oldukları bilinmektedir. Tercih aşamasında kurumsal bilgilere ilişkin beklentilerin yüksek olmasına neden olabilecek gerçek dışı, ya da fazla abartılı bilgilerin öğrencilerde hayal kırıklığı yaratabildiği ve hatta okuldan ayrılma eğilimi göstermelerine neden olduğu görülmektedir. Bu durum öğrencilerde memnuniyetsizlik yaratırken, kurumsal bilgilerin internet sitesinde gerçeğinden farklı olması, bu tür bilgilerin yayınlanmasında herhangi bir denetim olmadığını göstermektedir (Demir ve Demir, 2012). 
Yükseköğretimde farklı düzeyde eğitim gören öğrencilerin okul, bölüm ve program seçerken geleceğe yönelik düşünceleri ve beklentilerine göre karar verdikleri bir gerçektir. $\mathrm{Bu}$ nedenle eğitim kurumları öğrencilerin akademik başarısında olduğu gibi iş yaşamına hazırlık, uygulamalara yönelik teorinin kazandırılması ve bilginin paylaşımında belirli davranış ve alışkanlıkların edinilmesinde önemli işleve sahip olması nedeniyle, eğitim kalitesinin işgücü piyasasına yansıması da olumlu olabilmektedir (Kozak ve Coşar, 2009; Nelson, 2003; Willinsky, 2005). Öğrencilerin bilinçli tercih yapmasında eğitim kurumunun işgücü piyasasındaki itibarının yüksek olması etkili olurken, onların hem okuldan hem de iş piyasasından beklentilerinin de yüksek düzeyde oluşmasına neden olmaktadır (Emanuel ve Adams, 2006; VidaverCohen, 2007).

Turizmin öznesi insandır ve turizm gelirlerinin kaynağı, seyahat eden insanların bireysel harcamalarından oluşmaktadır (Emir ve Avan, 2010). Aynı şekilde Yükseköğretimin de öznesi insandır ve bu kurumlar öğrenciler sayesinde faaliyetlerine devam edebilmektedir. Bunun farkında olan Yükseköğretim Kurumları, öğrencilerin kendilerini tercih etmesi için "Farkında olmanın yeni yüzü", "Eğitimde, bilimde, sanatta çağdaş”, “Aydınlık yarınlara”, “Atatürk gençliğinin çağdaş, mutlu ve öncü üniversitesi”, "Tercih edilebilir bir üniversite", "Değer üreten üniversite", "Genç, üretken, nitelikli ve bilginin sevgiyle bütünleştiği bilge üniversite, "Profesyonel yaşam için doğru adım", "Uygulamalı eğitimde tartışılmaz seçenek üstünlüğü”, “Geleceğinizin başladığı yer: Bilinçli tercih, kaliteli eğitim, güvenli gelecek” gibi öğrenci merkezli üniversite sloganlarıyla onları önemsediklerini göstererek, kalite ve değer unsurunu ön plana çıkarırken bazıları da bu rekabet içinde var olma adına, yurt dışı eğitim ve diploma olanakları, kariyer geliştirme programları vb ulaşılması güç ve farklı uygulamalara yönelmektedir.

Yapılan bazı araştırmalar (Paramewaran ve Glowacka, 1995; Russell, 2005; Srikanthan ve Dalrymple, 2002), uluslararası alanda nitelikli öğrencilerin okul seçiminde eğitim kurumu imajının önemli olduğu ve kurumsal imajın aynı zamanda eğitim pazarlamasında üniversitelere rekabet üstünlüğü sağladığı ve buna bağlı olarak öğrenci beklentilerinin artmasına yol açtığını ortaya koymaktadır. Öğrencilerin kurumsal itibarı yüksek bir okuldan mezun olmalarının kolaylıkla iş ve staj yeri bulabileceklerine olan inancı, beklenti-memnuniyet ilişkisindeki algılamalarının farklı olmamasında etkisini gösterebilmektedir (Allen, Bourhis, Burrell ve Mabry, 2002; Athiyaman, 1997). Özellikle turizm sektöründeki işletmeler tarafından kurumsal itibarı olan bir üniversite öğrencisinin tercih edilmesi, öğrencilerin memnuniyet düzeylerinin artmasında önemli bir rol oynamaktadır. Diğer yandan yurt içi ve yurt dışı Farabi, Erasmus, Mevlana gibi değişim programları öğrenci eğitim memnuniyetinin sağlanmasında etkin unsurlardan biri olarak görülmekte (Demir ve Demir, 2012) ve bu tür olanakların öğrencilerin okul seçimini olumlu etkilediği bilinmektedir.

Öğrencilerin Yükseköğretim Kurumlarını seçim kararlarında oluşan beklentilerinin yalnızca akademik çalışmalar ve mesleki uygulamalara odaklamadığı bir gerçektir. Ancak eğitim kurumlarında internet siteleri üzerinden ulaşılabilen bilgilerin 
önemli oranda dikkate alındığı, öğrencilerin tercih sonrası, öğretim elemanlarının ders anlatma, araç-gereç vb. eğitim teknolojisini kullanma, öğretme tarzı vb konularda, beklenti-memnuniyet çalışmalarında açıkça ortaya çıkmaktadır (Demir ve Demir, 2012; Hallock, Satava ve LeSage, 2003). Diğer yandan, eğitim kurumlarının fiziki yapı ve donanımlarının modern görünümü ve teknolojik araç-gereç ve malzemelerle desteklemiş eğitim alanı olarak düzenlenmesi öğrencilere bir çekicilik yaratabilmekte ve teknolojik gelişmelere cevap verebilecek şekilde eğitim-öğretim teknikleriyle beklentilerin karşılanması hem öğrencilere hem de öğretim elemanlarına da olumlu katkılar sağlayabilmektedir (Palihawadana ve Holmes, 1999; Ramos, 1993; Soedijati ve Pratminingsih, 2011). Bu da öğrencilerin Yükseköğretim Kurumlarına yönelik tercihlerinde önemli etken olarak değerlendirilmektedir.

Yükseköğretimin önlisans, lisans ve lisansüstü düzeylerinde öğrenim görme amacıyla okul seçiminde farklı değerlendirmeler olması doğaldır. Bu üç düzeyde gerek okul seçimi ile koşullar, gerekse öğrenci profili ve amaçlar birbirinden farklılık göstermektedir. Önlisans düzeyi için sınavsız, lisans düzeyi için ÖSYM sınavları, lisansüstü eğitim için ALES ve yabancı dil sınavları ile öğrencilerin okullara yerleştirilmesi söz konusudur. $\mathrm{Bu}$ nedenle çalışmada üzerinde durulan konunun kavramsal boyutunda her üç düzey için gerekli koşulların sağlandığı varsayılarak araştırma bölümü bunun üzerine kurgulanmıştır. Bu kapsamda oluşturulan hipotezler aşağıda ifade edilmiştir;

- $\mathrm{H}_{1}$ :Öğrencilerin okul seçiminde kurumsal internet sitelerindeki bilgilerin boyutları arasında yükseköğrenim düzeylerine göre farklılıklar bulunur

- $\mathrm{H}_{2 \mathrm{a}}$ : Tüm yükseköğrenim düzeyindeki öğrencilerin okul seçiminde kurumsal imaj faktörü etkilidir

- $\mathrm{H}_{2 \mathrm{~b}}$ : Tüm yükseköğrenim düzeyindeki öğrencilerin okul seçiminde kurumun fiziki olanakları etkilidir

- $\mathrm{H}_{2 \mathrm{c}}$ : Tüm yükseköğrenim düzeyindeki öğrencilerin okul seçiminde kurumun akademik kadro durumu etkilidir

- $\mathrm{H}_{2 \mathrm{~d}}$ : Tüm yükseköğrenim düzeyindeki öğrencilerin okul seçiminde kurumun internet sitesinden bilgiye ulaşım etkilidir.

\section{Yöntem}

\section{Araştırma Modeli}

Çalışmada nicel araştırma yöntemi kullanılmıştır. Öncelikle, literatürden elde edilen benzer çalışmalardan geliştirilen ölçek kullanılmıştır. Ölçeğin güvenirlik ve geçerliğini sağlamak amacıyla ilk aşamada 44 kişi ile bir ön test yapılmıştır. İkinci aşamada 103 kişi ile bir uygulama yapılmış ve sonuçları Kültür ve Turizm Bakanlığı'nca 17-19 Ekim 2012 tarihleri arasında Ankara'da düzenlenen Turizm Eğitimi Konferans/Workshop'da sunulmuştur. Üçüncü aşamada ölçeğin bu çalışmada kullanılan son hali oluşturulmuştur. Kullanılan ölçeğin bu çalışmaya uygun, güvenirlik ve geçerliğin sağlanmış olması araştırma açısından önemli kolaylıklar sağlamıştır. Ölçekte 
yer alan bağımlı değişkenler öğrencilerin tercih yaparken vermiş oldukları kararı, bağımsız değişkenler ise bu kararı etkileyen faktörleri içermektedir.

\section{Araştırmanın Evren ve Örneklemi}

Türkiye'de Turizm alanında Önlisans, Lisans ve Lisansüstü Bölüm ve Programları düzeyinde eğitim veren okulların sayısı her geçen gün artmasına karşın hangi okulların aktif, hangilerinin ise henüz faaliyete geçtiği konusunda kesin bir bilgi olmadığı gibi okullarda fiili olarak eğitime devam eden öğrenci sayısı da kesin olarak bilinmemektedir. Çünkü üniversite kayıtlarına göre mevcut öğrenci sayıları olarak belirtilen rakamlar içinde öğrenim harcı vb yükümlülüklerini yerine getirmiş olup da okula devam etmeyenlerinde olduğu bilinmektedir. Araştırmanın evrenini Konya, İzmir, Muğla, Isparta, Antalya ve Mersin'deki devlet üniversitelerinde Önlisans, Lisans ve Lisansüstü düzeyde turizm eğitimi veren Yükseköğrenim kurumları oluşturmaktadır. Evrenin kesin olarak belirlenememesine rağmen bu kurumlarda yaklaşık olarak 15.000 civarında öğrenci bulunmakta olup, örneklemin \%95 güven düzeyinde 375 olmasının yeterli olacağı öne sürülmektedir (Sekaran, 2000; Yazıcıŏlu ve Erdoğan, 2004). Bununla birlikte, veri toplama araştırmacıların değerlendirmesine bağlı olarak tesadüfî örnekleme yöntemi kullanılarak gerçekleştirilmiştir. Araştırmanın verileri, 2011-2012 ve 2012-2013 Eğitim-Öğretim Y1llarında belirtilen devlet üniversitelerinde Önlisans, Lisans ve Lisansüstü düzeyde öğrenim gören öğrencilerden elde edilmiştir.

\section{Veri Toplama Aracı}

Araştırmada verilerin toplanmasında geliştirilen ölçeğin anket formuna dönüştürülerek basılı ve elektronik formattaki halinden yararlanılmıştır. Ölçek dört faktör grubu içinde yer alan 21 adet Likert türü soru ifadelerinden oluşmaktadır. Bununla birlikte 2 adet bağımlı değişken sorusu yer almaktadır. Bağımsız ve bağımlı değişkenlerin tamamı Likert türü 5'li aralıkta (1=en zayıftan ....5=en güçlüye katılım düzeyi) düzenlenmiştir. Veri toplama işleminin bir kısmı yüz yüze görüşme yapılarak, bir kısmı elektronik posta ve sosyal medya aracılı̆̆ı gerçekleştirilmiştir. Verilerin toplanmasında yapılandırılmış anket formu kullanılmıştır. Veri toplamada kullanılan anket formunda katılımcıların demografik bilgilerine yer verilmemiştir. Toplam 600 anketten geri dönen ve kullanılabilir olanların sayısı 396'dır. Bu rakam araştırma evreni için belirlenen örneklemin (375) üzerindedir.

\section{Veri Analizi ve Çözümlenmesi}

Verilerin analizinde PASW 18.0 istatistik paket programı kullanılmış, ulaşılan istatistiksel değerler oluşturulan tablolara aktarılmıştır. Bu aşamada, kullanılan ölçeğin önceden güvenirlik ve geçerlik yapılmış olmasına rağmen, daha çok katılımcı ile aynı analizler genel olarak tekrar edilmiştir. Aynı analizler ile parça güvenirliği de test edilmiştir. İkinci aşamada sırasıyla faktör analizi, korelasyon analizi, ANOVA ve regresyon analizi yapılmıştır.

\section{Bulgular}


Araştırmada elde edilen verilerin analiz edilmesinden sonra ulaşılan bulgular tablolar yardımıyla açıklanmaktadır. Toplam 396 adet anket değerlendirilmeye alınmıştır. Katılımcıların demografik özelliklerinin çalışmanın amacı ve içeriği ile doğrudan bir ilgisi olmadığı için yer verilmemiştir. Çalışmanın genel güvenirlik düzeyi $(\alpha=.89)$ sosyal bilimler için öngörülen değerin üzerinde gerçekleşmiş olması, diğer analizlere geçilebileceğini göstermektedir (Nunnally, 1978; Sekaran, 2000). Çalışmada yakınsak ve ayırt edici geçerlik analizinin de yapılmasıyla birlikte faktör analizinde oluşan yapı, kullanılan ölçekle örtüşmektedir. Yalnızca faktör gruplarının ağırlıkları ve değişkenlerin faktör yüklerinin kullanılan ölçekten farklı olduğu ve bunun da normal bir sonuç olarak kabul edildiği anlamlıdır. Analiz sonuçları itibariyle 4 grupta yer alan değişkenlere ilişkin faktör yükleri, özdeğer, açıklanan varyans oranı ve faktör güvenirlik düzeyine ilişkin bulgularda tablo1'de yer almaktadır.

"Kurumsal imaj" olarak belirlenen birinci faktör değişkenleri, eğitim kurumunun turizm sektöründe tanınması, yurt içi ve yurt dışı diğer eğitim kurumları ile işbirliği ve okul sonrası iş bulma kolaylığı ile ilgilidir. İstatistiksel olarak en yüksek değerlere sahip olan birinci faktör kullanılan ölçek (Demir ve Demir, 2012) ile benzer bulguları taşımaktadır. İkinci faktör grubunu oluşturan değişkenlerin eğitim kurumunun ders ve uygulama alanlarının fiziki durumu nedeniyle "fiziki olanaklar" olarak ifade edilmiştir. $\mathrm{Bu}$ faktör grubuna ilişkin bulgular kullanılan ölçek modelinden daha istatistiksel değerlere sahip olduğunu ortaya koymaktadır.

Üçüncü faktör "akademik kadro" olarak belirlenmiştir. Bu faktörü oluşturan değişkenlerin eğitim hizmetinin sağlanmasında aktif rol alan öğretim elemanları ile ilgili katılımcı algılamaları olduğu görülmektedir. Özellikle öğretim elemanlarının sektörel ve eğitim konusu ile ilgili yetkinlik ve yeterliliğe sahip olmasının daha yüksek değerler taşıdığı bulgusuna ulaşılmıştır. Son faktör grubunu "bilgiye ulaşım” oluşturmaktadır. Eğitim kurumunun internet sitesinde yer alan kurumsal bilgilerin içerik ve erişilebilme açısından katılımcıları tatmin etmesinin oldukça önemli olduğu anlaşılmaktadır. Faktör analizinde oluşan dört faktör grubunu temsil eden değişkenlerin istatistiksel olarak da geçerli olduğu görülmektedir.

Tablo 1

Faktör Analizi Sonuçları

$\begin{array}{lllllll}\text { Kurumun internet sitesinde yer alan bilgilerde... } & \text { FY } & \text { ÖZD } & \text { TFY } & \text { Ort. } & \text { p } & \alpha\end{array}$




\begin{tabular}{|c|c|c|c|c|c|c|c|}
\hline & Kurumsal İmaj & & 15.17 & 22.36 & 4.24 & .001 & .92 \\
\hline Kİ-1 & Mezunlarının iyi pozisyonlarda iş bulmaktadır & .912 & & & & & \\
\hline Kİ-4 & Öğrenciler kolay iş ve staj yerleri bulmaktadır & .901 & & & & & \\
\hline $\mathrm{KI}-3$ & Yurt dışı değişim programları bilgisi verilmektedir & .845 & & & & & \\
\hline $\mathrm{KI}-2$ & Yurt içi değişim programları bilgisi verilmektedir & .808 & & & & & \\
\hline \multirow[t]{2}{*}{ Kİ-5 } & Okul sektörde iyi tanınmaktadır & .796 & & & & & \\
\hline & Fiziki Olanaklar & & 8.28 & 18.11 & 4.09 & .001 & .90 \\
\hline FO-1 & Okul üniversite yerleşkesi içinde yer almaktadır & .898 & & & & & \\
\hline FO-3 & Ayrı uygulama tesisi bulunmaktadır & .877 & & & & & \\
\hline FO-2 & Mesleki uygulama alanı bilgisi mevcuttur & .824 & & & & & \\
\hline FO-6 & Okulun kendi binası bulunmaktadır & .801 & & & & & \\
\hline FO-5 & Sosyal alanlar bulunmaktadır & .719 & & & & & \\
\hline \multirow[t]{2}{*}{ FO-4 } & Yeterli derslik olduğu bilgisi mevcuttur & 689 & & & & & \\
\hline & Akademik Kadro & & 7.51 & 14.43 & 4.03 & .004 & .87 \\
\hline AK-3 & Turizm sektörü deneyimine sahiptir & .902 & & & & & \\
\hline AK-4 & Alanında isim yapmış kişilerdir & .865 & & & & & \\
\hline AK-1 & Hepsi alanında uzmandır & .793 & & & & & \\
\hline AK-2 & $\begin{array}{l}\text { Turizm eğitimi almış akademisyenlerden } \\
\text { oluşmaktadır }\end{array}$ & .782 & & & & & \\
\hline AK-5 & Hepsi doktora derecesine sahiptir & .727 & & & & & \\
\hline \multirow[t]{2}{*}{ AK-6 } & Sayısal olarak fazladır & .684 & & & & & \\
\hline & Bilgiye Ulaşım & & 6.03 & 11.13 & 3.98 & .009 & .85 \\
\hline BY-1 & İnternetteki kurumsal bilgilerden yararlandım & .874 & & & & & \\
\hline BY-2 & İnternette okulu sanal inceleme şansım oldu & .861 & & & & & \\
\hline BY-3 & Tercihimde okul e-posta adresinden bilgi aldım & .833 & & & & & \\
\hline \multirow[t]{2}{*}{ BY-4 } & Okulun internetteki tanıtım programlarına katıldım & .726 & & & & & \\
\hline & Seçim Kararı & & 5.69 & 10.06 & 4.37 & .001 & .88 \\
\hline
\end{tabular}

SK-1 Bilgiler tatmin edicidir

SK-2 Bilgiler tercih kolaylı̆̆ı sağladı

$\mathrm{KMO}=0.843$, Bartlett's Test of Sphericity $=3326.19 ; \mathrm{df}=228 ; \mathrm{Sig} .=0.000 ;$ Açıklanan Varyans $=\% 76.09$

Faktörler arasındaki ilişkileri belirlemek için korelasyon analizi yapılmıştır (Tablo 2). Çalışmanın temel amacının bağımlı değişken ile bağımsız değişkenlerin ilişkisi ve etkileşimi olduğu için bağımsız değişkenlerin kendi aralarında bulunan anlamlı ve pozitif bir ilişkinin üzerinde durulmamıştır. Bu kapsamda yalnızca bağımsız değişkenlerin oluşturduğu faktör grupları ile bağımlı değişkenin oluşturduğu faktör 
arasındaki ilişkilere yönelik bulgular dikkate alınmıştır. Kurumsal imaj ile seçim kararı pozitif yönlü, önemli düzeyde ve anlamlı bir ilişki bulunmaktadır(r=.72; $\mathrm{p}<.01)$.

Tablo 2

Korelasyon Analizi Sonuçları

\begin{tabular}{|c|c|c|c|c|c|c|c|c|}
\hline Faktörler & $\begin{array}{c}\text { Değişken } \\
\text { sayısı }\end{array}$ & Ort. & SS & 1 & 2 & 3 & 4 & 5 \\
\hline 1- Kurumsal İmaj & 5 & 4.24 & .72 & 1 & & & & \\
\hline 2- Fiziki Olanaklar & 6 & 4.09 & .81 & $.45^{* *}$ & 1 & & & \\
\hline 3- Akademik Kadro & 6 & 4.03 & .87 & $.68 * *$ & $.28^{*}$ & 1 & & \\
\hline 4-Bilgiye Ulaşım & 4 & 3.98 & .96 & $.53 * *$ & $.32 *$ & $.59 * *$ & 1 & \\
\hline 5-Seçim Kararı & 2 & 4.37 & .69 & $.72 * *$ & $.51 * *$ & $.63 * *$ & $.58 * *$ & 1 \\
\hline
\end{tabular}

Araştırmada ulaşılan bulgular öğrencilerin Yükseköğretim Kurumlarını tercihlerinde kurumsal imajı oluşturan değişkenlerin önemli olduğunu göstermektedir. Dolayısıyla öğrenciler okul seçimi yaparken yalnızca eğitim dönemi olanakları değil aynı zamanda mezuniyet sonrası dönemde de kurumun yaratmış olduğu imajdan yararlanmayı düşünmektedir. Öğrencilerin eğitim görmek istedikleri eğitim kumrunun fiziki olanaklarını önemsemeleri seçim kararları ile ilişkili olduğunu göstermektedir. "Fiziki olanaklar" faktörü ile "seçim kararı" faktörü arasında pozitif yönlü ve anlamlı bir ilişki olduğu analiz sonuçlarından anlaşılmaktadır $(\mathrm{r}=.51 ; \mathrm{p}<.01)$. Öğrencilerin eğitim kurumunu seçiminde akademik kadro ile ilgili yeterlik ve yetkinliklere de önem verdiği korelasyon analizinde "akademik kadro" ile "seçim kararı" faktörlerinin arasındaki pozitif yönlü, doğrusal ve anlamlı bir ilişkiden anlaşılmaktadır( $\mathrm{r}=.63 ; \mathrm{p}<.01)$. "Bilgiye Ulaşım" faktörü "seçim kararı" faktörü arasında da diğer faktör gruplarında olduğu gibi pozitif ve anlamlı bir ilişkinin olduğu bulgusuna ulaşılmıştır $(r=.58 ; p<.01)$.

Çalışmada faktör analizi ve korelasyon analizi sonuçlarına göre ulaşılan bulguların belirlenen amaçları ortaya koymak adına yeterli olmadığı bir gerçektir. Bu nedenle katılımcıların farklı eğitim düzeyinde olmaları ve eğitim düzeylerinin bireylerin değişkenleri algılamalarında farklılık olup olmadığının da belirlenmesi gerekmektedir. $\mathrm{Bu}$ amaçla farklı eğitim düzeylerindeki katılımcıların değerlendirmelerinin belirlemesi amacıyla ANOVA testleri yapılmıştır.

Tablo 3'de yer alan bulgular incelendiğinde değişkenlerinin farklı eğitim düzeyleri için farklı değerler içerdiği görülmektedir. Ancak bu farklılıkların rastlantısal mı yoksa gerçek bir durum göstergesi mi olduğunu belirleyebilmek için ANOVA tablosunu faktörler bazında ayrı ayrı incelemek gerekir. ANOVA tablosunun anlamlılık sütunundaki değerlerin $\mathrm{p}<.05$ olduğu görülmektedir. Söz konusu değerlerin 5 faktör 
grubunda da $\mathrm{p}<.05$ küçük olması, faktör grupları ile eğitim düzeyleri arasındaki ilişkinin $\mathrm{p}<.05$ düzeyinde istatistiksel olarak anlamlı olduğunu göstermektedir.

Tablo 3

Öğrencilerin Ĕ̆itim Düzeylerine Göre Karşılaştırma

\begin{tabular}{|c|c|c|c|c|c|c|}
\hline Faktörler & $\begin{array}{l}\text { Eğitim } \\
\text { düzeyi }\end{array}$ & $\mathrm{N}$ & Ort. & SS & $\mathrm{F}$ & $\mathrm{P}$ \\
\hline \multirow[t]{3}{*}{ 1- Kurumsal İmaj } & Önlisans & 159 & 3.80 & 1.22 & 77.82 & .001 \\
\hline & Lisans & 145 & 4.18 & 0.96 & & \\
\hline & Lisansüstü & 92 & 4.36 & 0.89 & & \\
\hline \multirow[t]{3}{*}{ 2- Fiziki Olanaklar } & Önlisans & 159 & 4.14 & 0.91 & 61.04 & .001 \\
\hline & Lisans & 145 & 4.02 & 0.95 & & \\
\hline & Lisansüstü & 92 & 3.86 & 1.19 & & \\
\hline \multirow[t]{3}{*}{ 3- Akademik Kadro } & Önlisans & 159 & 3.01 & 1.64 & 40.19 & .004 \\
\hline & Lisans & 145 & 4.21 & 0.91 & & \\
\hline & Lisansüstü & 92 & 4.74 & 0.62 & & \\
\hline \multirow[t]{3}{*}{ 4-Bilgiye Ulaşım } & Önlisans & 159 & 3.57 & 1.37 & 39.76 & .009 \\
\hline & Lisans & 145 & 4.11 & 0.99 & & \\
\hline & Lisansüstü & 92 & 4.33 & 0.93 & & \\
\hline \multirow[t]{3}{*}{ 5-Seçim Kararı } & Önlisans & 159 & 3.72 & 1.21 & 47.42 & .001 \\
\hline & Lisans & 145 & 4.05 & 0.89 & & \\
\hline & Lisansüstü & 92 & 4.68 & 0.69 & & \\
\hline
\end{tabular}

Varyansların homojenliği testi (Homogeneity of variance test) sonuçlarına göre anlamlılık değerinin p $>0.05$ olarak gerçeklemiş varyansların homojen dağılmış olması nedeniyle Scheffe testi uygulanmıştır. ANOVA testinde farklı eğitim düzeylerinde olan öğrencilerin, faktör gruplarının algılamasında ulaşılan ortalama değerler arasındaki farkın anlamlı olması, hangi ikili gruplar arasındaki farkın anlamlı olduğuna ilişkin bilgi vermediği için, Scheffe testi tablosunun faktörler ve eğitim düzeyleri bazında incelenmesini zorunlu kılmaktadır.

Okul seçiminde belirlenen faktörler ile verilen seçim kararı konularında öğrenim düzeyleri arasında farklılık algılanıp algılanmadığının belirlenmesi amacıyla yapılan ANOVA analizlerine göre tüm faktörler için öğrenim düzeyleri arasında farklılık olduğu ortaya çıkmıştır. Ancak ikili gruplar arasında anlamlı bir farklılık olup olmadığını belirlemek için yapılan Scheffe Testi sonuçlarında bazı karşılaştırmalarda anlamlı bir farklılığın olmadığı bulgusuna ulaşılmıştır. Kurumsal imajın öğrenim düzeylerine göre 
farklılık gösterdiği bir gerçektir. Diğer bir deyişle öğrenim düzeyi arttıkça eğitim kurumunun imajına verilen önemin de $\operatorname{artt1ğ} 1$, bu değerlendirmenin de istatistiksel olarak anlamlı farklılık yarattığı görülmektedir. Öğrencilerin Yükseköğretim Kurumu seçiminde "fiziki olanaklar"ın karar vermelerinde öğrenim düzeylerine göre bir farklılık oluşturup oluşturmadığı konusunda yapılan karşılaştırmalarda Önlisans-Lisans ( $p=.084)$ ve Lisans-Lisansüstü $(p=.056)$ düzeyleri için anlamlı bir farklılığın olmadığ görülmektedir ( $>$ >.05). Buna karşın karar verme sürecinde Önlisans öğrencilerinin Lisansüstü öğrencilere göre eğitim kurumunun fiziki olanaklarına daha fazla önem verdikleri görülmekte ve bu karşılaştırmada anlamlı bir farklılık ortaya çıkmaktadır.

Tablo 4

Post-Hoc Testleri (Scheffe)

\begin{tabular}{|c|c|c|c|c|c|}
\hline Faktörler & $\begin{array}{c}\text { Eğitim } \\
\text { düzeyi (I) }\end{array}$ & $\begin{array}{c}\text { Eğitim } \\
\text { düzeyi (J) }\end{array}$ & Fark (I-J) & S. Hata & $\mathrm{p}$ \\
\hline \multirow[t]{3}{*}{ 1- Kurumsal İmaj } & Önlisans & Lisans & -.38 & 0.18 & .014 \\
\hline & Önlisans & Lisansüstü & -.56 & 0.20 & .001 \\
\hline & Lisans & Lisansüstü & -.18 & 0.20 & .009 \\
\hline \multirow[t]{3}{*}{ 2- Fiziki Olanaklar } & Önlisans & Lisans & .12 & 0.17 & .084 \\
\hline & Önlisans & Lisansüstü & .28 & 0.19 & .037 \\
\hline & Lisans & Lisansüstü & .16 & 0.18 & .056 \\
\hline \multirow[t]{3}{*}{ 3- Akademik Kadro } & Önlisans & Lisans & -1.20 & 0.20 & .003 \\
\hline & Önlisans & Lisansüstü & -1.73 & 0.21 & .001 \\
\hline & Lisans & Lisansüstü & -.53 & 0.17 & .001 \\
\hline \multirow[t]{3}{*}{ 4-Bilgiye Ulaşım } & Önlisans & Lisans & -.54 & 0.19 & .021 \\
\hline & Önlisans & Lisansüstü & -.76 & 0.19 & .001 \\
\hline & Lisans & Lisansüstü & -.22 & 0.20 & .004 \\
\hline \multirow[t]{3}{*}{ 5-Seçim Kararı } & Önlisans & Lisans & -.33 & 0.21 & .007 \\
\hline & Önlisans & Lisansüstü & -.96 & 0.18 & .001 \\
\hline & Lisans & Lisansüstü & -.63 & 0.18 & .001 \\
\hline
\end{tabular}

Eğitim görülecek Yükseköğretim Kurumlarının seçiminde, kurumların akademik kadro durumunun öğrenim düzeylerine göre farklılık gösterdiği, öğrenim düzeyi arttıkça akademik kadronun önemsenme düzeyinin de buna paralel olarak arttığı görülmektedir. Dolayısıyla Önlisans düzeyindeki öğrenciler için eğitim kurumunun akademik kadrosu çok fazla önemsenmez iken Lisansüstü düzeyde bunun daha önemli olduğu belirlemiştir. Diğer bir deyişle, Lisansüstü düzey; Lisans ve Önlisans düzeylerine, Lisans düzey de; Önlisans düzeyine göre akademik kadro durumunu farklı algılamaktadır. Analiz sonuçları internete yer alan kurumsal bilgilerden yararlanma konusunda öğrenim düzeylerine göre bir farklılık olduğu, bu farklılığın da anlamlı 
olduğu bulgusunu ortaya koymaktadır. Öğrencilerin Yükseköğretim Kurumu seçim kararlarında öğrenim düzeyleri arasında anlamlı bir farklılık oluştuğu görülmektedir.

Tablo 5

Regresyon Analiz Sonuçları

\begin{tabular}{|c|c|c|c|c|c|c|}
\hline \multirow{3}{*}{$\begin{array}{c}\text { BAĞIMSIZ } \\
\text { DEĞISSSKENLER }\end{array}$} & \multicolumn{6}{|c|}{ BAĞIMLI DEĞIŞKEN: OKUL SEÇIMM KARARI } \\
\hline & \multicolumn{2}{|c|}{ ÖNLISANS } & \multicolumn{2}{|c|}{ LISANS } & \multicolumn{2}{|c|}{ LİSANSÜSTÜ } \\
\hline & $\beta$ & $\mathrm{t}$ & $\beta$ & $\mathrm{t}$ & $\beta$ & $\mathrm{t}$ \\
\hline SABİT & & 13.025 & & 19.442 & & 22.106 \\
\hline 1- Kurumsal İmaj & .178 & $2.114 *$ & .149 & $4.027 * *$ & .126 & $6.712 * *$ \\
\hline 2- Fiziki Olanaklar & .141 & $5.404 * *$ & .154 & $3.998 * *$ & .197 & 1.611 \\
\hline 3- Akademik Kadro & .202 & 1.482 & .138 & $4.616^{* *}$ & .128 & $7.882 * *$ \\
\hline 4-Bilgiye Ulaşım & .165 & $2.488 * *$ & .143 & $4.854 * *$ & .136 & $7.904^{*}$ \\
\hline F & 61.26 & & 44.57 & & 50.63 & \\
\hline $\mathrm{R}$ & .41 & & .44 & & .48 & \\
\hline $\mathrm{R}^{2}$ & .22 & & .24 & & .25 & \\
\hline Düzeltilmiş R ${ }^{2}$ & .20 & & .22 & & .23 & \\
\hline
\end{tabular}

$* * \mathrm{p}<.01 ; * \mathrm{p}<.05$

Öğrencilerin Yükseköğretim Kurumlarını seçerken dikkate aldıkları kurumsal internet sitesi içeriğinin karar vermeleri üzerindeki etkisini belirlemek amacıyla yapılan regresyon analizi farklı öğrenim düzeylerine göre ulaşılan bulgular tablo 5'te görülmektedir. Regresyon analizinde bağımsız değişkenler bir blok olarak tek adımda girilip "enter metodu” ile değerlendirilmiştir. "Kurumsal İmaj” faktörünün öğrencilerin okul seçim kararlarını olumlu etkilediği görülmektedir. Farklı öğrenim düzeylerinde etkili olan kurumsal imajın Önlisans düzeyinde $(\mathrm{t}=2.114$ ve $\mathrm{p}<.05)$, Lisans düzeyinde $(\mathrm{t}=4.027$ ve $\mathrm{p}<.01)$ ve Lisansüstü düzeyde $(\mathrm{t}=6.712$ ve $\mathrm{p}<.01)$ seçim kararlarında anlamlı olması Lisansüstü düzeyde diğerlerine göre daha belirgindir. $\mathrm{Bu}$ sonuç Lisansüstü öğrenim düzeyindeki öğrencilerin eğitim görecekleri Yükseköğretim Kurumunun imajını önemsediğini göstermektedir.

Regresyon analizi sonuçlarında Yükseköğretim Kurumunun "Fiziki Olanakları"nın öğrencilerin okul seçim kararları üzerinde Önlisans ( $\mathrm{t}=5.404$ ve $\mathrm{p}<.01)$ ve Lisans ( $\mathrm{t}=3.998$ ve $\mathrm{p}<.01)$ düzeylerinde etkili olduğu görülürken Lisansüstü $(\mathrm{t}=1.611$ ve p>.05) düzeyde bir etkisinin olmadığı anlaşılmaktadır. Lisansüstü düzeyde öğrenim gören öğrencilerin fiziki olanaklar dışında başka etkenleri önemsedikleri açıkça söylenebilir. Yükseköğretim Kurumunun fiziki olanaklara sahip olmasının Önlisans düzeyinde öğrenim gören öğrenciler açısından daha fazla önemli görülmesinin temelinde üniversiteye geçiş sisteminde sahip oldukları kolaylıklar etken olabilir. 
Yükseköğretim Kurumunun resmi internet sitelerinde yer alan "Akademik Kadro" bilgisi ve durumunun farklı düzeyde öğrenim gören öğrencilerin okul seçim kararlarında farklı bulgular sunduğu görülmektedir. Önlisans düzeyindeki öğrencilerin okul seçim kararlarında akademik kadro yapısının önemli bir etkisinin olmadığı analiz sonuçlarıyla da istatistiksel olarak desteklenmektedir ( $\mathrm{t}=1.482$ ve $\mathrm{p}>.05)$. Buna karşın akademik kadro durumu Lisans ve Lisansüstü öğrenim düzeylerinde öğrenci kararlarında etkili olmaktadır. Lisansüstü eğitim düzeyinde $(t=7.882$ ve $p<.01)$, Lisans eğitim düzeyine $(\mathrm{t}=4.616$ ve $\mathrm{p}<.01)$ göre bu etkinin daha belirgin olduğu bir gerçektir. $\mathrm{Bu}$ da Lisansüstü düzeyde öğrenim gören öğrencilerin okul seçimlerinde akademik kadro durumunun nitelik ve niceliksel olarak daha fazla dikkate alındığını göstermektedir.

Öğrencilerin okul seçimlerinde Yükseköğretim Kurumunun internet sitesi aracılığı ile "Bilgiye Ulaşım” konusundaki çabaları onların karar vermelerinde etkili olduğu regresyon analizi sonuçları ile ortaya konulmuştur. Tablo 5 incelendiğinde ulaşılan bulguların anlamlı düzeyde etkili olduğu ancak bu etkinin farklı öğrenim düzeylerine göre değiştiği açıktır. Öğrenci okul seçimi kararlarında, bilgiye ulaşımda en belirgin anlamlı etkinin Lisansüstü düzeyde öğrenim görenlere ait olduğu ( $t=7.904$ ve $\mathrm{p}<.01)$, bunu sirasıyla Lisans düzeyinde öğrenim görenler $(\mathrm{t}=4.854$ ve $\mathrm{p}<.01)$ ve Önlisans düzeyinde öğrenim görenler izlemektedir ( $\mathrm{t}=2.488$ ve $\mathrm{p}<.01$ ).

Çalışmada oluşturulan hipotezlerin test edilmesiyle $\mathrm{H}_{1}$ hipotezinin kabul edildiği görülmektedir. Diğer yandan $\mathrm{H}_{2 \mathrm{a}}$ ve $\mathrm{H}_{2 \mathrm{~d}}$ hipotezleri tüm yükseköğrenim düzeyindeki öğrencilerin okul seçim kararlarını etkilemesi nedeniyle kabul edilirken, $\mathrm{H}_{2 b}$ ve $\mathrm{H}_{2 \mathrm{c}}$ hipotezleri tüm yükseköğrenim düzeyleri için geçerli sonuçları içermemektedir. $\mathrm{H}_{2 b}$ ve $\mathrm{H}_{2 \mathrm{c}}$ hipotezlerinin farklı öğrenim düzeyleri için farklı sonuçlar doğurduğu bir gerçektir.

\section{Sonuç ve Tartışma}

Yükseköğretim Kurumlarında öğrenim gören öğrenciler farklı öğrenim düzeylerinde turizm eğitimi almaktadır. Önlisans öğrencilerinin büyük çoğunluğu mezun oldukları liselerin bulunduğu bölge ve yaşadıkları şehir ve/veya yakın yerlerdeki Yükseköğretim Kurumlarına ÖSYM'nin yapmış olduğu sınav ya da sınavsız olarak doğrudan geçiş yapabilmektedir. Lisans düzeyinde öğrenim görenler ise ÖSYM tarafından yapılacak olan merkezi yerleştirme sınavlarına göre Yükseköğretim Kurumlarına yerleştirilmektedir. Diğer yandan Lisansüstü düzeyde öğrenim görenlerde öncelikli koşul; ALES ve Yabancı Dil sınav sonuçları, sonraki aşamada ise, ilgili Yükseköğretim Kurumlarının değerlendirmesidir. Hangi düzeyde olursa olsun öğrencilerin öğrenim görecekleri Yükseköğretim Kurumlarını, koşullarını sağlamaları durumunda kendilerinin seçebilmesidir. İşte bu aşamada öğrencilerin seçim kararlarında Yükseköğretim Kurumlarının resmi internet siteleri aracılığıyla sunduğu bilgiler önemli rol oynamaktadır. Daha önceki yapılan bazı çalışmalarda (Abdulkadiroğlu ve Sönmez, 2003; Soedijati ve Pratminingsih, 2011; Srikanthan ve Dalrymple, 2002) bunu desteklemektedir. Bu çalışmada, Yükseköğretim Kurumlarının internet sitelerinde yer alan bilgilerin, öğrencilerin okul seçim kararlarını ne derecede etkilediği üzerinde durulmuştur. Genel olarak kurumsal internet sitelerinde yer alan bilgilerle seçim kararı 
arasında bir ilişki olduğu ortaya çıkmıştır. Bilgilerin öğrenciler açısından ne kadar fazla çekiciliğe sahip olursa, seçim kararlarını da aynı oranda olumlu bir şekilde etkilediği belirlenmiştir. Ancak bu ilişkilerin farklı öğrenim düzeylerine göre algılamasının da farklı olduğu bir gerçektir. Bu farklılığın temelinde her düzeydeki öğrencilerin farklı amaçlara sahip olması kadar Yükseköğretim Kurumlarına giriş sistemlerinin de birbirinden farklılık gösterebilmesinin olduğu söylenebilir.

Öğrencilerin Yükseköğretim Kurumlarını seçimlerinde kurumsal imajın her öğrenim düzeyinde de seçim kararlarını etkilemesi, gerek eğitim dönemi gerekse mezuniyet sonrası onlara sağlayacağ psikolojik tatmin ve iş yaşamında sağlayacağı yararlar açısından değerlendirilebilir. Öğrencinin gözünde Harvard, Oxford, Cambridge, ODTÜ, Boğaziçi gibi kurumsal imaja sahip üniversiteler her zaman önemli yer tutmaktadır. Öğrenci bu okulları bitirdiğinde iş yaşamına diğerlerinden bir adım önde başlayacağını düşünmektedir (Demir ve Demir, 2012). Kurumsal imajın Lisansüstü öğrenim düzeyindeki öğrenciler tarafından daha yüksek düzeyde önemsenmesi, onların akademisyen olma amacıyla iyi bir eğitim kurumunda yetişme düşüncelerini ön plana çıkardığını ortaya koymaktadır. Ancak bunu genellemek, günümüz şartlarında pek de kolay değildir (Paramewaran ve Glowacka, 1995). Diğer yandan, Yükseköğretim Kurumlarının fiziki olanakları Önlisans düzeyindeki öğrenciler açısından önemli görülmesine karşın Lisansüstü düzeydeki öğrenciler tarafından önemsenmemesi her öğrenim düzeyindeki öğrencilerin okul seçimindeki bakış açılarını da ortaya koymaktadır. Bir tarafta akademik kariyer için amaçları önceden belirli ve net olan bir grup, diğer tarafta ise henüz ne amaçla okula geldiğini açıç̧a ortaya koyamayan diğer grup bulunmaktadır. Dolayısıyla Yükseköğretim Kurumlarının fiziki olanakları iyi eğitim almada önemli yararlar sağlayabilir, ancak amaca ulaşmada en önemli etken değildir. $\mathrm{Bu}$ durum Lisans düzeyindeki öğrenci değerlendirmelerinin orta düzeyde önemsenmesiyle de desteklenmektedir. Çünkü bu grup içinde bilinçli tercih yaparak amaçları belli olanlar ile henüz karar verememiş olanlar yer almaktadır.

Yükseköğretim Kurumlarının akademik kadro yapısı konusunda kurumsal internet sitelerindeki bilgiler öğrenci tercihlerini genel olarak etkilemektedir. Ancak istisnai durumlar da söz konusudur. Çalışmada Lisans ve Lisansüstü düzeylerinde öğrenim gören öğrencilerin Yükseköğretim Kurumlarının internet sitelerinde yer alan akademik kadro durumunun seçim kararlarını etkilediği görülürken Önlisans düzeyindekilerin seçim kararlarında bu faktörün bir etkisi olmadığı ortaya çıkmıştır. Buradan çıkarılacak bir sonuçta; Önlisans düzeyindeki öğrencilerin genel olarak Yükseköğretim Kurumlarına bilinçli olarak gelmedikleri, yalnızca üniversite ortamı yaşama amacında oldukları gerçeği, hem akademik kadro faktörünün önemsenmemesi hem de onlar için fiziki olanakların daha önemli olması şeklindeki değerlendirmeleriyle kanıtlanmaktadır. Özellikle turizm bölümlerinde okuyan Önlisans düzeyindeki öğrencilerin çoğunluğunun Turizm Lisesi çıkışlı olması ve turizm sezonlarında sektörde çalışma olanaklarının ve iş bağlantılarının olması da onların okul seçiminde farklı düşüncelerinin olabileceğini ortaya koymaktadır. Öğrencilerin Yükseköğretim Kurumlarını seçerken kurumsal internet sitelerinde yer alan bilgilerden yararlanma ya 
da e-posta ve iletişim kanalları aracılığıyla bilgi talep ederek seçim kararlarını verdikleri de çalışmada ortaya çıkan sonuçlardan birisidir.

Sonuç olarak öğrencilerin Yükseköğretim Kurumlarını tercih ederken internet sitesindeki bilgilerden yararlandığı, internet sitesi içeriklerinin farklı boyutlarıyla öğrencilerin seçim kararlarını etkilediği ortaya çıkmıştır. Ancak Yükseköğretim Kurumlarının farklı öğrenim düzeyindeki öğrenci algılamalarına göre bu etkilenme de değişmektedir. Diğer yandan bu çalışmada ulaşılan bulgular, yalnızca turizm alanında eğitim veren Yükseköğretim Kurumları ve onların farklı öğrenim düzeylerine ilişkin sonuçları oluşturmuştur. Ayrıca elde edilen bulgular ve sonuçlar devlet üniversitelerinde öğrenim gören öğrencilere aittir. Dolayısıyla çalışmada ortaya çıkan sonuçların turizm dışında diğer alanlarda eğitim görenler ile özel üniversiteleri de kapsayacak şekilde genellenmesi doğru değildir. Bundan sonra yapılacak araştırmaların, hem devlet üniversiteleri, hem de vakıf üniversitelerini ve turizm dışında diğer alanları da kapsayacak şekilde yapılması, Yükseköğretim Kurumlarının seçiminde öğrenci kararlarını etkiyen etkenlerin belirlenmesi ve sonuçları açısından önemlidir.

\section{Kaynakça}

Abdulkadiroğlu, A. \& Sönmez, T. (2003). School choice: A mechanism design approach. American economic review, 729-747.

Allen, M., Bourhis, J., Burrell, N., \& Mabry, E. (2002). Comparing student satisfaction with distance education to traditional classrooms in higher education: A metaanalysis. The American Journal of Distance Education, 16 (2), 83-97. 
Athiyaman, A. (1997). Linking student satisfaction and service quality perceptions: the case of university education. European Journal of Marketing, 31 (7), 528-540.

Bonn, M.A., Furr, H.L. \& Susskind, A.M. (1998). Using the internet as a pleasure travel planning tool: An examination of the sociodemographic and behavioral characteristics among internet users and non-users. Journal of Hospitality and Tourism Research, 22(3), 303-317.

Bussel, H. (1998). Parental choice of primary school: an application of Q-methodology. Service Industries Journal, 18 (3), 135-147.

Bussell, H. (2000). Choosing a school: the impact of social class on the primary school decision-making process. International Journal of Nonprofit and Voluntary Sector Marketing, 5 (4), 373-387.

Chen, Y. \& Sönmez, T. (2006). School choice: an experimental study. Journal of Economic theory, 127 (1), 202-231.

Coşkun, N. (2004). Elektronik ticaretin gelişiminde temel dinamikler ve gelişimi önündeki engeller. Çukurova Ünv., Sos. Bil. Ens. Dergisi, 13 (2), 243-258.

Demir, M. \& Demir, Ş.Ş. (2003). Konaklama işletmelerinde elektronik bilgi sisteminin (EBS) işgörenler üzerindeki etkilerinin araştırılması. Anatolia; Turizm Araştırmaları Dergisi, 14 (1), 56-64.

Demir, Ş.Ş. \& Demir, M. (2011). Turizm lisans öğrencilerinin akademik beklentimemnuniyet düzeyinin kariyer planlamasına etkisi. I. Uluslararast Turizm ve Otelcilik Sempozyumu-UTOS'11, 29 Eylül-01 Ekim 2011, Beyşehir, Konya.

Demir, Ş.Ş. \& Demir, M. (2012). Turizm eğitimi veren yükseköğretim kurumlarının web sayfasında yer alan bilgilerin öğrencilerin okul seçimi kararlarına etkisi. Turizm Eğitimi Konferans / Workshop, 17-19 Ekim 2012, Ankara.

Emanuel, R. \& Adams, J.N. (2006). Assessing college student perceptions of instructor customer service via the quality of instructor service to students (QISS) questionnaire.Assessment \& Evaluation in Higher Education, 31 (5), 535-549.

Emir, O. \& Avan, A. (2010). Yabancı turistlerin satınalma karar sürecinde kültürel varlıkların etkisi: Konya Örneği. Selçuk Üniversitesi Sosyal Bilimler Enstitüsü Dergisi, 24, 203-219.

Hallock, D., Satava, D. \& LeSage, T. (2003). An exploratory investigation of the potential relationship between student learning styles, course grade, cumulative grade point average and selected demographics in on-line undergraduate business courses. Management Research News, 26 (1), 21-28.

Hastings, J.S. \& Weinstein, J.M. (2008). Information, school choice, and academic achievement: Evidence from two experiments. The Quarterly Journal of Economics, 123 (4), 1373-1414. 
Hoxby, C.M. (2003). School choice and school productivity. Could school choice be a tide that lifts all boats? In The economics of school choice (pp. 287-342). Chicago: University of Chicago Press.

Hoxby, C.M. (2007). The economics of school choice. Chicago:University of Chicago Press.

Kozak, M. \& Coşar, Y. (2009). How decision strategies and school-based pull factors associate with students' choice of tourism schools. Journal of Hospitality, Leisure, Sport \& Tourism Education, 8 (2), 74-82.

Nelson, R. (2003). Student efficiency: A study on the behavior and productive efficiency of college students and the determinants of GPA". Issues in Political Economy, 12, 32-43.

Nunnally, J.C. (1978). Psychometric Theory. New York: McGraw-Hill.

Palihawadana, D. \& Holmes, G. (1999). Modelling module evaluation in marketing education. Quality Assurance in Education, 7 (1), 41-46.

Paramewaran, R. \& Glowacka, A.E. (1995). University image: An information processing perspective. Marketing for Higher Education, 6 (2), 41-56.

Ramos, M. (1993). Evaluation, recognition, and reward of academic advising. In Margaret King (Ed.). Academic advising: Organizing and delivering services for student success (pp. 63-74), San Francisco: Jossey-Bass.

Russell, M. (2005). Marketing education: A review of service quality perceptions among international students. International Journal of Contemporary Hospitality Management, 17 (1), 65-77.

Sarıfakığlu, B. (2013). İnternetin toplumsal etkileri. http://www.emo.org.tr/ekler/ d5flfd8442d4ba6_ek.pdf?dergi=483. (Erişim Tarihi: 14.01.2013).

Schneider, M., Teske, P.E. \& Marschall, M. (2002). Choosing schools: Consumer choice and the quality of American schools. Princeton University Press.

Sekaran, U. (2000). Research Methods for Business: A Skill Building Approach. New York: John Wiley \& Sons Inc.

Soedijati, E.K. \& Pratminingsih, S.A. (2011). The impacts of marketing mix on students' choice of university study case of private university in Bandung. Indonesia. 2nd International Conference on Business and Economic Research (2nd ICBER 2011) Proceeding, 2124-2131.

Srikanthan, G. \& Dalrymple, J.F. (2002). Developing a holistic model for quality in higher education. Quality in Higher Education, 8 (3), 215-224.

Uçak, N.Ö. \& Güzeldere, Ş.O. (2006). Bilişsel yapının ve işlemlerin bilgi arama davranışı üzerine etkisi. Türk Kütüphaneciliği, 20 (1),7-28. 
Vidaver-Cohen, D. (2007). Reputation beyond the rankings: A conceptual framework for business school research. Corporate Reputation Review, 10 (4), 278-304.

Weiher, G. R. \& Tedin, K. L. (2006). Minority student achievement. Review of Policy Research, 23 (5), 963-967.

Werthner, H. \& Klein, S. (1999). Information Technology and Tourism: A Challenging Relationship. Wien: Verlag.

Whitmore, E. (2002). Disciplinary differences and undergraduates' information-seeking behavior. Journal of the American Society for Information Science and Technology, $53(8), 631-638$.

Willinsky, J. (2005). Just say know? Schooling the knowledge society. Educational Theory, 55 (1), 97-111.

Yazıcıŏlu, Y. \& Erdoğan, S. (2004). SPSS Uygulamalı Bilimsel Araştırma Yöntemleri. Ankara: Detay Yayıncılık.

Yolal, M. \& Kozak, R. (2008). Bilgiye erişim aracı olarak öğrencilerin internete yaklaşımı. Dumlupınar Üniversitesi Sosyal Bilimler Dergisi, 20, 115-128. 